\title{
Assessing quality of life in Australian patients with Graves' ophthalmopathy
}

\author{
J J Park, T J Sullivan, R H Mortimer, M Wagenaar, D A Perry-Keene
}

Br J Ophthalmol 2004;88:75-78

\begin{abstract}
Aims: To determine quality of life and adequacy of education and counselling in Australian patients with Graves' ophthalmopathy during the course of their illness.

Methods: A cross sectional study was conducted at the orbital and endocrinology clinics of Royal Brisbane Hospital on 162 consecutive patients with Graves' ophthalmopathy who were managed between the 1992 and 2000. The Graves' ophthalmopathy quality of life (GO-QOL) survey modified for Australian conditions was distributed to study participants. Of the 19 questions asked, nine questions related to visual functioning, eight questions were about the psychosocial consequences of changed appearance, and two questions referred to education and counselling. Additionally, clinical data on the severity of illness were collected retrospectively from the medical notes of these patients.

Results: Completed questionnaires were received from 128 patients. The majority of patients reported limitations in daily activities such as hobbies, driving, watching television and reading, as well as impaired self confidence. The mean GOQOL scores in this study were (100 representing maximum QOL): visual functioning 59.0 (SD 28.0), psychosocial consequences of changed appearance 54.5 (28.4), and education and counselling 59.1 (38.8). Only about a quarter of patients indicated that education and counselling were adequate and helpful.

Conclusion: Graves' ophthalmopathy profoundly affects $\mathrm{QOL}$ and adequate education and counselling are essential for helping patients to cope with their illness. The GO-QOL survey is a simple, practical tool that can be used easily in a clinic to determine the QOL issues in subjects with Graves' ophthalmopathy.
\end{abstract}

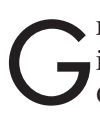
raves' ophthalmopathy (GO) is a chronic, debilitating infiltrative eye disease that is often associated with Graves' disease or occasionally with Hashimoto's thyroiditis. GO may be severely disabling because of ocular discomfort, as well as its effect on vision and appearance. About $50 \%$ of patients with Graves' disease will develop Graves' ophthalmopathy. ${ }^{1}$ The clinical features and management of GO have been well documented previously but it is only recently that attention has been drawn to the impaired quality of life (QOL) perceived by patients with GO. ${ }^{2-5}$

QOL of patients with GO was investigated using a health questionnaire (Medical Outcome Study Short-Form General Health Survey and Sickness Impact Profile) and published by Gerding and co-workers. ${ }^{2}$ The study showed little correlation between measures of activity and severity of disease and the scores on the QOL questionnaire, ${ }^{2}$ The authors reported that patients with mild or moderately severe GO had similar or worse QOL impairment than patients suffering from heart failure, pulmonary emphysema, and diabetes mellitus. ${ }^{2}$ General questionnaires are, however, not sensitive to some of the unique problems experienced by patients with GO. Terwee and co-workers have developed a disease specific health related quality of life survey that has been tested and validated on a Dutch cohort of patients. ${ }^{3}{ }^{4}$ This instrument has been used to measure the change in QOL score associated with clinically important improvements in clinical signs resulting from treatment. ${ }^{5}$ A detailed study looking at QOL issues and the utility of education and counselling in patients with GO has not, however, been reported in an English speaking population.

We used an English language GO quality of life survey modified for local conditions for patients seen at a tertiary institution over the previous 8 years. The aim of the study was to measure impairment of QOL during the illness. In addition, we asked if education and counselling helped patients cope with their illness. It is a simple survey that has applications in clinical practice.

\section{METHODS}

The English language translation of the GO-QOL survey provided by Terwee and colleagues from the Netherlands was modified to suit the Australian population. The original instrument has 18 questions divided into two sections, visual functioning and psychosocial consequences. A question about effects of diplopia and impaired visual acuity on cycling was replaced by two questions about effects on work and carrying out domestic duties. An additional section containing two questions about the effects of education and counselling on quality of life was also added (see appendix). The questionnaire was scored as described by Terwee and coworkers. This QOL survey was specifically designed for GO and is not designed for use with other health conditions.

We asked patients with GO seen at the orbital and endocrinology clinics of the Royal Brisbane Hospital between 1992 and 2000 to complete the modified GO-QOL survey. We included 162 consecutive patients (age 17-82 years) with Graves' ophthalmopathy. To be eligible for the survey, clinical data were obtained retrospectively from the medical notes and all patients were clinically and biochemically euthyroid at the time of completing the survey. The study was approved by the Royal Brisbane Hospital's research ethics committee and written consent was obtained before participation. All patients received the modified GO-QOL self administered questionnaires via either postal mail (majority) or during outpatient clinic consultations and were asked to consider QOL issues during the course of their illness. The majority of questionnaires were returned by postal mail over a 2 month period or completed at the outpatient clinics immediately. Four weeks after the last mailing, non-responders were contacted and the questionnaires were posted again if requested. 


\begin{tabular}{|ll|}
\hline Table 1 & Patient demographics \\
\hline Variable & Value $(\mathbf{n}=\mathbf{1 2 8})$ \\
\hline Age (years) & \\
Mean & 48.5 \\
Range & $17-82$ \\
Sex & $106(82 \%)$ \\
Female & $22(18 \%)$ \\
Male & \\
NOSPECS overall clinical & \\
severity categories & $12(9.4 \%)$ \\
Minimal signs (o) & $81(63.3 \%)$ \\
Mild to moderate (a-b) & $35(27.3 \%)$ \\
Severe (c) & \\
\hline
\end{tabular}

The 1977 NOSPECS classification ${ }^{6}$ was used to record clinical severity of the illness at the time of its maximal severity, as recorded in the medical notes. Comparison was made with QOL scores. Ophthalmopathy was divided into three overall grades_-severe, mild to moderate, and minimal. Patients with clinical signs corresponding to NOSPECS classes 2-6 with "grade c" were assigned to severe disease category, patients with "grades a and/or b" were assigned to mild to moderate disease category, and those patients in classes 0 or 1 was assigned to minimal disease category.

Relations between sections of the QOL instrument were assessed by Spearman's rank correlation. Analysis of variance was done with Bonferroni post hoc analysis. The $\chi^{2}$ was used to compare two categorical data. Statistical calculations were done with the software program Systat 9 (Systat Inc, Evanston, IL, USA).

\section{RESULTS}

Questionnaires were distributed to all 162 eligible participants, 128 of whom completed the questionnaires $(79 \%$ response rate). Of the 34 non-participants, 29 had changed their contact details or were unavailable and five patients did not wish to participate in the survey. Twenty five surveys contained one unanswered question and two surveys had two unanswered questions. These items were recorded as missing values. We found the modified English GO-QOL survey simple for patients to use, being relatively short (less than 7 minutes to complete), with simple layout and format. Demographic details and clinical severity of ophthalmopathy are shown in table 1.

The frequencies of responses to each of the questions are shown in tables 2,3 , and 4 . In all, $72 \%$ of patients felt that GO interfered with their visual function in some way and $63 \%$ patients felt their changed appearance had significantly interfered with psychosocial functioning. The majority reported limitations in daily activities such as hobbies, driving, watching television, and reading, as well as impaired self confidence. A total of $74 \%$ of patients felt that education and counselling were inadequate and unhelpful in coping with and understanding thyroid eye disease. The mean QOL scores (range 0-100) stratified according to the overall clinical severity is shown in figure 1. There were no significant correlations between scores in subsections of the QOL survey.

The effect of clinical severity as judged by clinical scores on QOL was examined by analysis of variance. Increasing clinical severity was associated with impaired quality of life from poor visual function and changed appearance. Patients with clinical severity scores in the severe range had

Table 2 Frequencies of responses from questions on visual functioning $(n=128)$ (nine questions)

\begin{tabular}{lllll}
\hline $\begin{array}{l}\text { Limitations in carrying } \\
\text { out the following activities }\end{array}$ & $\begin{array}{l}\text { Severely limited } \\
(\%)\end{array}$ & $\begin{array}{l}\text { Little limited } \\
(\%)\end{array}$ & $\begin{array}{l}\text { Not limited } \\
(\%)\end{array}$ & $\begin{array}{l}\text { Missing response } \\
(\%)\end{array}$ \\
\hline 1 Hindered from doing & 34 & 38 & 24 & 4 \\
something wanted to do. & 31 & 40 & 29 & 0 \\
2 Reading & 24 & 45 & 30 & 1 \\
3 Watching TV & 24 & 36 & 36 & 4 \\
4 Hobbies or pastimes & 16 & 43 & 25 & 0 \\
5 Driving * & 15 & 40 & 28 & 3 \\
6 At work (usual job) ** & 18 & 35 & 47 & 2 \\
7 Walking outdoors & 4 & 41 & 49 & 1 \\
8 Performing domestic duties & 8 & 29 & 68 & \\
9 Moving around the house & 2 & & &
\end{tabular}

The other responses for these questions were "no driver's licence" $(16 \%)^{*}$ and "no work" $(14 \%)^{* *}$.

Table 3 Frequencies of responses from questions on psychosocial consequences as a result of changed appearance $(n=128)$ (eight questions)

\begin{tabular}{lllll}
\hline $\begin{array}{l}\text { Psychosocial consequences } \\
\text { because of thyroid eye } \\
\text { disease }\end{array}$ & Very much (\%) & A little (\%) & No (\%) & $\begin{array}{l}\text { Missing response } \\
\text { (\%) }\end{array}$ \\
\hline $\begin{array}{l}\text { 1 Appearance has changed } \\
\text { 2 Influence on self confidence }\end{array}$ & 63 & 27 & 10 & 0 \\
3 Stared in the streets & 27 & 33 & 23 & 0 \\
$\begin{array}{l}\text { 4 Appear less often on photos } \\
\text { than before }\end{array}$ & 52 & 41 & 32 & 0 \\
5 Mask changes in your & 28 & 13 & 35 & 0 \\
$\begin{array}{l}\text { appearance } \\
\text { 6 Socially isolated }\end{array}$ & 13 & 36 & 35 & 1 \\
7 People react unpleasantly & 11 & 30 & 56 & 1 \\
8 Influence on making friends & 12 & 30 & 59 & 0 \\
\hline
\end{tabular}




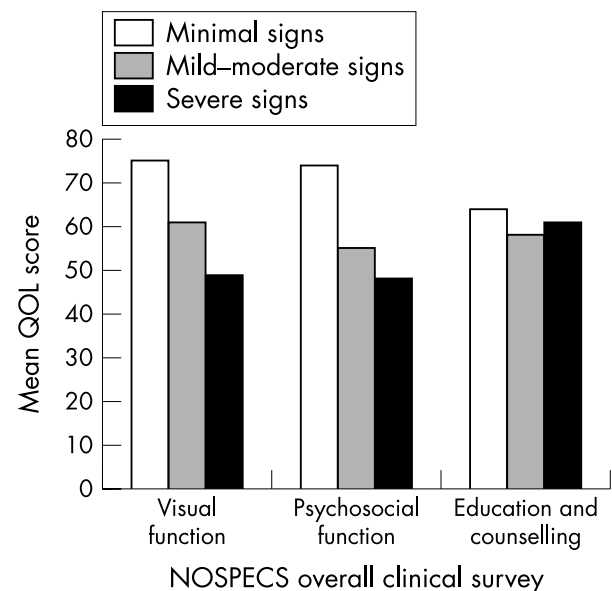

Figure 1 Mean QOL scores $v$ NOSPECS overall clinical severity.

significantly worse quality of life from impaired visual function $(p=0.017)$ and psychosocial consequences of changed appearance $(p=0.013)$ than those with minimal disease. Older patients (between 60-80 years of age) reported a greater impact of changes in visual function (mean QOL score 61.7) than changed appearance on QOL (mean QOL score 73.1 ).

\section{DISCUSSION}

GO has significant impact on the lives of these patients, with the majority of respondents reporting limitation in daily activities such as hobbies, driving, watching television, and reading, as well as impaired self confidence because of changes in appearance. Unlike previous studies ${ }^{23}$ we found significant relations between the severity of illness as measured by the NOSPECS system and impaired quality of life.

In educating and counselling, it was our objective to elicit the difficulties experienced by patients and to provide information necessary for patients to understand their disease in order to cope with its various manifestations during its long course. In our consultations we have provided information brochures and suggested coping strategies to patients in dealing with their illness. Approximately three quarters of respondents reported that efforts to educate and counsel them were inadequate and unhelpful (table 4). This could be explained as patients may have perceived education and counselling as a separate event rather than part of consultation process itself. It could also reflect a need for better skills on the part of attending physicians and suggests that management of patients with GO could be improved. Nevertheless, it emphasises the importance of the counselling and education process in helping these patients cope with their illness, as there was high degree of statistical

Table 4 Frequencies of responses from questions on education and counselling ( $n=126$ ) (two questions)

\begin{tabular}{lllll}
\hline $\begin{array}{l}\text { Do you feel education } \\
\text { and counselling } \\
\text { concerning thyroid } \\
\text { eye disease (TED) }\end{array}$ & $\begin{array}{l}\text { Very much } \\
\text { (\%) }\end{array}$ & Little (\%) & No (\%) & $\begin{array}{l}\text { Missing } \\
\text { response (\%) }\end{array}$ \\
\hline $\begin{array}{l}1 \text { Helped you cope } \\
\text { and understand TED }\end{array}$ & 26 & 33 & 41 & 0 \\
2 Was adequate & 25 & 29 & 45 & 1 \\
\hline
\end{tabular}

significance between the questions concerning adequacy of education and counselling and coping with illness $(\mathrm{p}<0.01$, $\left.\chi^{2}, \mathrm{df}=4\right)$ - that is, those who thought education and counselling to be adequate indicated that it greatly helped them cope with their illness. Conversely, those who indicated that education and counselling did not help them cope with the illness thought that it was inadequate. As physicians become aware of such changes to lifestyle that lead to poor QOL in patients with GO, they would be able to offer patients better counselling and education on the likely effects of the disease.

Previous studies have reported low correlation between QOL scores and clinical severity and activity of GO and this has been explained as QOL is a subjective measure of patients' experiences that is distinct from clinical objective measures. ${ }^{2}$ Other studies on chronic illnesses also found weak correlation between the clinical measures and the quality of life assessments. ${ }^{7-10}$ The present study, however, found a significant relation between clinical estimates of severity of illness and impaired quality of life. It is possible that this results from an over-representation of severe cases in this study (because of referral to a tertiary centre of a large number of complicated cases such as optic nerve dysfunction and corneal exposure). It is also possible that these results could be attributable to temporal difference between collection of clinical data and completion of QOL survey.

Although there was weak correlation between the QOL scores and age, it does appear to have some influence in determining the responses to QOL issues appropriate for the age group. For example, older patients (between 60 and 80 years) scored higher QOL scores for psychosocial consequences section compared to visual functioning section, indicating that they were more concerned about limitations in vision related tasks and less concerned about resulting changes in appearance. As younger subjects gained more benefit from education and counselling than did older patients, this suggests that age appropriate education and counselling would need to be addressed and could be examined further in future studies.

In addition to addressing the traditional "biomedical" model in care of patients with Graves' ophthalmopathy, those involved in their care will be able to improve their management by understanding the important effects of GO on quality of life that this instrument brings to attention. The modified GO-QOL survey is a short, simple, self administered questionnaire that can be used in a clinical setting to evaluate this important topic.

\section{ACKNOWLEDGEMENTS}

We thank Caroline Terwee for providing us with the GO-QOL questionnaire. We also thank Dr David Sibritt of Centre for Clinical Epidemiology and Biostatistics, University of Newcastle, New South Wales, Australia, for his assistance with the statistical analysis of the data.

\section{Authors' affiliations \\ J J Park, T J Sullivan, Eyelid, Lacrimal and Orbital Clinic, Royal Brisbane Hospital, Qld 4029, Australia \\ R H Mortimer, M Wagenaar, D A Perry-Keene, Department of Endocrinology, Royal Brisbane Hospital, Qld 4029, Australia}

The authors do not have any propriety interest in any of the material used in the study.

Correspondence to: Associate Professor T J Sullivan, 7th Floor, 135 Wickham Terrace, Brisbane QLD 4000, Australia; tjs@gil.com.au

Accepted for publication 16 April 2003

Presented at the 33rd Annual Scientific Congress of Royal Australian and New Zealand College of Ophthalmologists, October 2001, Adelaide, Australia. 


\section{APPENDIX}

The modified GO-QOL questionnaire.

The following questions deal specifically with your thyroid eye disease

Please focus on the course of your illness whilst answering these questions

During the course of your illness, to what extent were you limited in carrying out the following activities, because of your thyroid eye disease?

\section{REFERENCES}

1 Coday MP, Netland PA, Dallow LD. Thyroid-associated ophthalmopathy (Graves' disease). In: Albert DM, Jacobiec FA, Azar DT, Gragoudas ES, eds. Principles and practice of ophthalmology, 2nd ed. Philadelphia: WB Saunders, 2000:4742-59.

2 Gerding MN, Terwee CB, Dekker FW, et al. Quality of life in patients with Graves' ophthalmopathy is markedly reduced: measurement by the medical outcomes study instrument. Thyroid 1997;7:885-9.
3 Terwee CB, Gerding MN, Dekker FW, et al. Development of a disease specific quality of life questionnaire for patients with Graves' ophthalmopathy: the GO-QOL. Br J Ophthalmol 1998;82:773-9.

4 Terwee CB, Gerding MN, Dekker FW, et al. Test-retest reliability of the GOQOL: a disease specific quality of life questionnaire for patients with Graves' ophthalmopathy. J Clin Epidemiol 1999;52:875-84.

5 Terwee CB, Dekker FW, Mourits MP, et al. Interpretation and validity of changes in scores on the Graves' ophthalmopathy quality of life questionnaire (GO-QOL) after different treatments. Clin Endo 2001;54:391-8.

6 Werner S C. Modification of the classification of the eye changes of Grave Disease: Recommendation of the Ad Hoc Committee of The American Thyroid Association. J Clin Endocrinol Metab 1977:44:203-4.

7 Frimodt-Moller PC, Jensen KM, Iversen $P$, et al. Analysis of presenting symptoms in prostatism. J Urol 1984;132:272-6.

8 Alonso J, Anto JM, Gonzalez M, et al. Measurement of general health status of non-oxygen-dependent chronic obstructive pulmonary disease patients. Med Care 1992;30:MS125-35.

9 Peterson WL, Sturdevant RAL, Frankl HD, et al. Healing of duodenal ulcer with an antacid regimen. N Eng J Med 1977;297:341-5.

10 Wiesel SW, Tsourmas N, Feffer HL, et al. A study of computer-assisted tomography, I: the incidence of positive CAT scans in an asymptomatic group of patients. Spine 1984;9:549-51.

Tick the box that matches your answer. The boxes correspond with the answers above them. Please tick only one box for each question.

\begin{tabular}{|c|c|c|c|c|}
\hline & Yes, severely limited & Yes, a little limited & No, not at all limited & No driver's licence \\
\hline $\begin{array}{l}\text { 1. Driving } \\
\text { 2. At work (usual job) } \\
\text { 3. Performing domestic duties (cooking etc...) } \\
\text { Moving around the house } \\
\text { Walking outdoors } \\
\text { 6. Reading } \\
\text { Watching TV } \\
\text { 8. Hobby or pastime, i.e......... } \\
\text { 9. During the course of your illness, did you feel } \\
\text { hindered from doing something that you wanted to do } \\
\text { because of your thyroid eye disease? }\end{array}$ & $\begin{array}{l}\square \\
\square \\
\square \\
\square \\
\square \\
\square \\
\square \\
\square \\
\text { Yes, severely hindered } \\
\square\end{array}$ & $\begin{array}{l}\square \\
\square \\
\square \\
\square \\
\square \\
\square \\
\square \\
\square \\
\text { Yes, a little hindered } \\
\square\end{array}$ & $\begin{array}{l}\square \\
\square \\
\square \\
\square \\
\square \\
\square \\
\square \\
\square \\
\text { No, not at all hindered } \\
\square\end{array}$ & $\begin{array}{l}\square \\
\square\end{array}$ \\
\hline
\end{tabular}

The following questions deal with your thyroid eye disease in general

\begin{tabular}{|c|c|c|c|}
\hline & Yes, very much so & Yes, a little & No, not at all \\
\hline $\begin{array}{l}\text { 10. Do you feel that your appearance has changed } \\
\text { because of your thyroid eye disease? }\end{array}$ & $\square$ & $\square$ & $\square$ \\
\hline $\begin{array}{l}\text { 11. Do you feel that you are stared at in the streets } \\
\text { because of your thyroid eye disease? }\end{array}$ & $\square$ & $\square$ & $\square$ \\
\hline $\begin{array}{l}\text { 12. Do you feel that people react unpleasantly because } \\
\text { of your thyroid eye disease? }\end{array}$ & $\square$ & $\square$ & $\square$ \\
\hline $\begin{array}{l}\text { 13. Do you feel that your thyroid eye disease has an } \\
\text { influence on your self confidence? }\end{array}$ & $\square$ & $\square$ & $\square$ \\
\hline $\begin{array}{l}\text { 14. Do you feel that your thyroid eye disease has an } \\
\text { influence on making friends? }\end{array}$ & $\square$ & $\square$ & $\square$ \\
\hline $\begin{array}{l}\text { 15. Do you feel socially isolated because of your thyroid } \\
\text { eye disease? }\end{array}$ & $\square$ & $\square$ & $\square$ \\
\hline $\begin{array}{l}\text { 16. Do you feel that you appear less often on photos } \\
\text { than before you had thyroid eye disease? }\end{array}$ & $\square$ & $\square$ & $\square$ \\
\hline $\begin{array}{l}\text { 17. Do you try to mask changes in your appearance } \\
\text { caused by thyroid eye disease? }\end{array}$ & $\square$ & $\square$ & $\square$ \\
\hline $\begin{array}{l}\text { 18. Do you feel patient education and counselling } \\
\text { concerning thyroid eye disease was adequate? }\end{array}$ & $\square$ & $\square$ & $\square$ \\
\hline $\begin{array}{l}\text { 19. Do you feel patient education and counselling } \\
\text { helped you cope with and understand thyroid eye disease? }\end{array}$ & $\square$ & $\square$ & $\square$ \\
\hline
\end{tabular}

